\title{
Research on Sculpture Art and Aesthetic Standards in Qin and Han Dynasties
}

\author{
Luo Chengwu, Jiang Wenying \\ Nanchang University, Jiangxi, Nanchang, China
}

Keywords: Qin and Han Dynasties; sculpture art; aesthetic standards

\begin{abstract}
Qin and Han Dynasties were the first important period for the establishment and development of our feudal system, which had a profound impact on the construction of all aspects of later generations. As a response to real life and certain aesthetic standards, art can not only influence the aesthetics and culture of people at that time, but also have a certain guiding effect on the development of later art. This paper mainly studies the sculpture art and its aesthetic standards in Qin and Han Dynasties.
\end{abstract}

\section{Introduction}

Sculpture is one of the seven art forms. Therefore, excellent sculpture works not only have a high artistic value, but also greatly promote the level of people's aesthetic appreciation. The Qin and Han Dynasties were the first period of development and prosperity of China's feudal society, and also the initial stage of the establishment and development of China's feudal system. The study of sculpture art and its aesthetic standards in this period is of great significance to the research and development of ancient Chinese sculpture art and modern sculpture art.

\section{The Necessity of Studying the sculpture Art and Its Aesthetic Standards in Qin and Han Dynasties}

First, to understand the overall development of sculpture art and culture in the Qin and Han Dynasties. The Qin and Han Dynasties were the first era of feudal unification in China, and also the first time that the development of sculpture art in China achieved epoch-making achievements. The sculpture art of this period is mainly based on realism and simplicity, focusing on the depiction of "reality". Through the study of sculpture art in this period, it is beneficial for us to form and deepen the overall understanding of sculpture art in the Qin and Han Dynasties and even the culture and art of this period, and thus accelerating the development of ancient Chinese culture and art research.

Second, to see the actual life of the residents in the Qin and Han Dynasties. Art comes from life and reflects life. The most important feature of sculpture art in the Qin and Han Dynasties was realism. Through the study of sculpture art in the Qin and Han Dynasties, we can help people to see the life of people at that time and learn more about the early development of feudal society.

Third, to testify whether some historical events are true. Through the study of sculpture art in the Qin and Han Dynasties, it is roughly speculated to restore the actual social life at that time. It helps people to use these known information to prove whether some historical events are true or to explain the rationality of their existence, such as Xiang Yu's ability to carry the allusions of tripod and so on.

\section{Research on Sculpture Art in Qin and Han Dynasties}

\subsection{An analysis of the representative works of sculpture in Qin and Han Dynasties}

After the first emperor of Qin unified the whole country and established the first feudal great unified dynasty in Chinese history, he used sculpture art to publicize his achievements and strengthen the kingship. Therefore, the sculpture art from Qin to the Eastern Han Dynasty developed rapidly. Among them, the more famous works are the Terracotta Warriors, Stone carvings in the tomb of Huo Qubing and the Plate for Gold and Copper Fairy. 
The first is the Terracotta Warriors, which is the tomb burial sculpture group built by the First Emperor of Qin for himself. It is also the largest and most representative tomb sculpture representative of the Qin Dynasty. The Terracotta Warriors not only have a large number of sculptures, but also a wide variety of sarcophagi, different stone figurines types of sergeants, standing soldiers, kneeling soldiers and military officers are included. Former French President Jacques Chirac called it "the eighth wonder of the world" ${ }^{[1]}$. In terms of creative style, it is based on realism, clear and bright, and the ranks and mood fluctuations of each military figure can be distinguished from the clothing, costumes, movements and expressions of each sculpture character; In terms of creative techniques, the combination of painting and plastics was used, and the works would be painted and colored after the sculpture steps were completed. Although it has been around for a long time, the colors on the faces and costumes of the characters are still faintly visible. From the overall layout, the whole structure of the Terracotta Warriors is strict, the army warriors have a clear division of labor and are orderly arranged, expression is solemn, showing the strong national strength of the state of Qin and the determination of the unified six countries at that time.

Next is the Stone Carvings of General Huo Qubing in the Han Dynasty. The Stone Carvings of carvings at the Tomb of Huo Qubing are the earliest large stone carvings that are found to be the earliest and most intact and also of the highest artistic value. It mainly shows the main achievements and the hard fighting life of Huo Qubing. The most famous one is the Horse Stepping on a Xiongnu Soldier Stone Carving ${ }^{[2]}$. The Horse Stepping on a Xiongnu Soldier Stone Carvingis the main body of the sculptures in the stone carvings. The overall shape is an proud horse standing on the foot of a hungry warrior with a bow and arrow weapon. The whole style is strong and powerful. The carving of the war horse and the warrior is vivid. The powerful muscles and mighty wartime assembly of the horses portrayed the handsome and brave of the war horse. The struggling movements and painful expressions of the Xiongnu warrior who was stepped on the feet were visible, even the beards of the face. This not only shows the development of carving technology and heroic image of Huo Qubing, but also shows the strong power of the Han Dynasty.

The last is the Plate for Gold and Copper Fairy. The Plate for Gold and Copper Fairy was made by the Martial Emperor of Han Dynasty for his immortality. According to records, in the late period of the Martial Emperor of Han Dynasty ruling, he began to search for immortals. He asked for a long life and built many Taoist longevity buildings. Later, he heard that taking amrita could prolong life to immortal, then he did not hesitate to spend a lot of manpower, material resources and financial resources to build a 20-foot sacred dish fairy in the Bailiang Palace. According to historical records, the whole plate is composed of three parts: The below undertaking column, a fairy to Hold the plate in the middle and the golden and copper plate in top. There are various kinds of auspicious flowers on the column. The immortal's modelling is also moving and elegant, showing the Taoist immortal color everywhere. But later, the plate was still destroyed by the fire. But according to the records, there is also a plate in Jianzhang Palace. Later, the Emperor Ming of Wei commanded to move it to the palace of the national capital. Before the removing, tears came out of the fairy's eyes. Li He, a famous poet of the Tang Dynasty, he used this to write the famous poem "Gold and copper fairy to say goodbye to Han" and sent out the feeling that "If Heaven had feelings, it too would age $\mathrm{e}^{[3] "}$.

\subsection{The characteristics of the sculpture art during Qin and Han Dynasties}

First, there are many kinds. The development of sculpture in the Qin and Han Dynasties was very rapid. It has made great achievements in architectural decorative sculptures, bronze memorial sculptures and tomb sculptures ${ }^{[4]}$. This has a great political reason for the rulers to strengthen the imperial power and consolidate the rule, as well as the role of the feudal system gradually established, the strength of the state gradually rising, and the social and economic development of the people's living standard.

Second, the style is diverse, and people pay attention to the realism. The carving art of the Qin Dynasty is generally composed of realistic elements. In the use of creative techniques, the combination of painting and plastic is often used. On the basis of the grand and solemnity of the 
Qin Dynasty, the Han Dynasty sculptures have added some creators' personal imagination and creative personality. Such as the use of symbolism, the combination of realism and romanticism, etc. There have also been some sculptures that have placed great hopes of the people.

Third, following up the past and ushering in the future. From the development of sculpture art in the Qin Dynasty, the sculpture art of the Qin Dynasty not only inherits the simple and solemn style characteristics of the pre-Qin sculpture, but also enriches the sculpture techniques and types. There are not only bronze memorial sculptures, but also stone and wood carvings. In addition, the use of coloured drawing technology has made the sculptures more vivid. From the development of sculpture in Han Dynasty, the Han Dynasty inherited the Qin system not only in terms of political economy, but also in culture and art. In addition to the magnificent and solemn features of the Qin Dynasty, the sculptures of Han Dynasty also joined in the vigorous and firm features of the times. This is closely related to the strength of the Han Dynasty and the wars with Xiongnu. And also carved many animals, especially horses. This is inseparable from the use of symbolism in sculpture. From the development of sculpture art in the later ages, the sculpture art in Qin and Han dynasties had a profound influence on the skills, styles and creative ideas of later sculptures. Therefore, the sculpture art in Qin and Han Dynasties has the characteristics of following up the past and ushering in the future.

\section{Research on the Aesthetic Standards of Sculpture Art in Qin and Han Dynasties}

\subsection{The aesthetic standards of sculpture art in Qin and Han Dynasties}

First, from the creative style, it pays attention to realism. Although the sculpture art of the Qin and Han dynasties has changed in both techniques and styles, the biggest feature of both is still realistic. The discovery and unearthed of the Terracotta Warriors is the best proof for the realism of the Qin Dynasty. Although the Han Dynasty sculpture increases the vigorous style and the use of symbolism, its most prominent still remains realism. From the overall shape of the sculpture, people can still clearly see the content and emotions reflected in the works, and there is no abstraction and exaggeration that does not conform to the facts and people's thinking. Therefore, the basic style and aesthetic standards of sculpture art in the Qin and Han Dynasties are still realistic.

Second, the Han Dynasty inherits the Qin system. According to the previous elaboration, the content of the Han Dynasty inherits the Qin system is also reflected in the aesthetics of literature and art. The sculpture art of the Han Dynasty inherited the characteristics and requirements of magnificent and solemn, practical and plastic in the Qin Dynasty. At the same time, it has also developed and infused new ways of expressing strength and symbolizing euphemism. In the Horse Stepping on a Xiongnu Soldier Stone Carving in the tomb of Huo Qubing, the horse symbolizes the fearlessness of the general army and the strength of the Han Dynasty. The Plate of Golden and Copper Fairy shows the political situation at that time from the side. These are all manifestations of the new development of the aesthetic standards of sculpture art in the Han Dynasty. Therefore, the "The Han Dynasty inherits the Qin system" of sculpture art means that the Han Dynasty sculpture not only inherits the aesthetic characteristics of the Qin Dynasty sculpture, but also has new development.

Thirdly, from the overall shape, the overall shape of the sculpture art in the Qin and Han Dynasties presented a clear and bright style, but there were differences in the details. The sculptures of the Qin Dynasty are too solemn and serious in the realism, giving people a heavy sense of oppression. This has a lot to do with the harsh law of the Qin Dynasty. The strict rule of being punished for being related to or friendly with someone who has committed an offence makes the people live in the harsh rule of high pressure for a long time, and the spirit is extremely tight and depressed. This is manifested in the lack of vitality in the sculptures; The sculptures of the Han Dynasty show more of the national strength and vitality from the overall shape, with some life temperature in the grace. In this period, the religious sculptures gradually developed and formed their own sculptural styles, such as the Longmen Grottoes in Luoyang and the Leshan Giant Buddha in Sichuan. 
Fourth, from the category of sculpture, the range of sculptures is constantly expanding. The sculpture types of the Qin Dynasty are mainly character sculptures and object sculptures. Especially in the tombs of the royal family, there are many human sculptures and funerary objects, and most of them are army warriors and slaves. The sculptures are more vivid through the means of painting; The scope of sculpture in the Han Dynasty increased the theme of animals, especially the depiction of horses, not only in a large number, but also in a variety of postures. This is mainly due to several wars between the Han Dynasty and the Xiongnu. Horse is not only one of the main tools of war, but also of a small number, and it is very precious. Therefore, the Han Dynasty's integration of horses into sculpture art is not only a display of powerful national power, but also a celebration of heroes.

\subsection{Significance and role of studying the aesthetic standards of sculpture in Qin and Han Dynasties}

First, to promote the development of aesthetic research on ancient Chinese sculptures and the inspiration of contemporary sculpture art. As the beginning period of China's feudal era, the Qin and Han Dynasties laid a certain foundation for the development of all aspects of feudal society in China, and the same in the development of art. Therefore, strengthening and deepening the study of the aesthetic standards of sculpture art in the Qin and Han Dynasties will help to supplement and improve the imperfect research of ancient Chinese sculpture art, accelerate the aesthetic study of ancient sculpture art. At the same time, this also has an enlightening effect on the aesthetic development of contemporary sculpture art.

Second, to improve people's aesthetic appreciation. The art of any period reflects the aesthetic standards of people at a certain stage of development, and it helps to improve people's aesthetic level. The study of the aesthetic standards of sculpture art in the Qin and Han Dynasties will help people to understand more about the development and aesthetic standards of sculpture art in the Qin and Han Dynasties, accumulate more art knowledge and aesthetic experience, absorb nutrients from classical sculpture art, and continuously improve artistic appreciation of viewers.

\section{Conclusion}

The Qin and Han Dynasties were the stage in which the feudal society of our country was established and gradually developed. The sculpture art of this period has developed rapidly with the intentional manipulation of the rulers, and has entered and completed the first peak period of the development of sculpture art in China. The sculpture art of this period not only reflects the common realistic features, but also shows the unique characteristics of the times in the respective political rule. It has exerted far-reaching influence on the development of sculpture art in China, and also helps people to improve their aesthetic appreciation ability.

\section{References}

[1] Tiantian Zhao. A comparison of sculpture between Chinese Qin and Han Dynasties and thwe golden time in ancient Greece and Rome[J]. West Leather, 2017, 39(4):94-95.

[2] Qingjing Luo. Research on the transformation of Qin and Han sculpture styles according to the Terracotta Warriors and the carvings in the Tomb of Huo Qubing[D]. Jiangxi Normal University, 2016.

[3] Yuanshu Ma, Huiqin Zhang. Comparison of aesthetic similarities and differences between the Qin and Han Dynasties and Byzantine periods--Women's code based on imperial court power[J]. Design, 2016(6):142-143.

[4] Xu Tan. The features of the Qin and Han statues--the artistic styles of vigorous, natural, vivid and lifelike[J]. Artistic, 2016(2):89-89. 